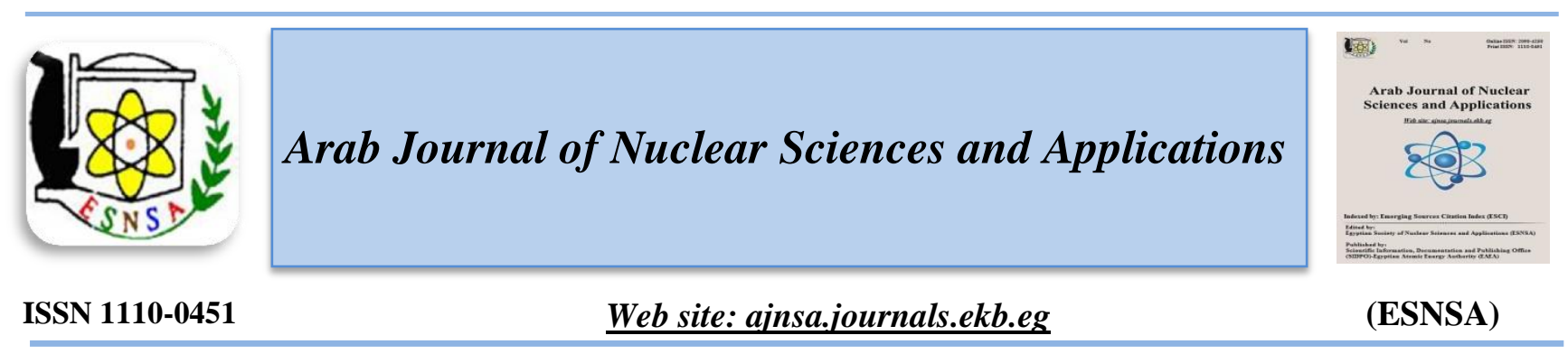

\title{
Anti-Tumor Effect of Green Tea Extract, Simvastatin and Gamma Radiation on Solid Tumor in Mice
}

\author{
Ibrahim Y. Abdelrahman ${ }^{1^{*}}$, Hausein El-Kashef ${ }^{1}$, Nagwa H. A. Hassan ${ }^{2}$ \\ ${ }^{1}$ Egyptian Atomic Energy Authority, National Center for Radiation Research and Technology, Cairo, Egypt \\ ${ }^{2}$ Zoology Department, Faculty of Science, Ain Shams University, Cairo, Egypt \\ Received $21^{\text {st }}$ Jan. 2020 The current study was conducted of six groups $(n=12)$ to define the efficacy of epigallocatechin gallate, \\ Accepted $5^{\text {th }}$ Aug. 2020 simvastatin and gamma radiation individually or combined together to reduce solid tumor size induced \\ by intramuscular injection of EC cells in the right thigh of the targeted mice. Magnetic resonance \\ imaging device (1.5 Tesla) used for radiology imaging of the normal and ascites-bearing mice under \\ anesthesia. The animals with solid tumors were followed up daily for recording deaths, tumor size, rate \\ of inflammation and gangrene in the tumor area of hind limb. Magnetic resonance imaging showed the \\ intraperitoneal ascites and the soft organs (liver, kidney and intestine) which were bright in the case of \\ ascites-bearing mouse than the normal control. Triple therapy regimen significantly reduced the tumor \\ size $(662.6 \pm 12.5)$ compared to the positive control $(825 \pm 21.8)$ and increased survival rate to $66.7 \%$ \\ compared to $25 \%$ in the positive control. Triple therapy reduced the inflammation of tumor area, \\ preventing the gangrene incidence, and showed the best value of $\mathrm{T} / \mathrm{C}=142, \mathrm{ILS}=42.11$ and $\mathrm{TIR} \%=19.6$ \\ compared to the positive control and single treatments, hence, it is considered an anti-tumor regimen \\ according to the National Cancer Institute criteria.
}

\section{Introduction}

Keywords: Solid Tumor, Green Tea extract, Simvastatin, Gamma radiation, MRI, Combination Therapy
Cancer is considered the real enemy which threats population at the present time. Some researchers all over the world devoted their efforts to find the best drug that could prevent or treat cancer without any side effects on the normal cells. Recent statistics, according to global studies showed that about 14.1 million persons were recorded in 2012 and it is expected, in future, to reach 19.3 millions who will suffer from cancer by 2025 [1]. GLOBOCAN 2018 estimated that there were 18.1 million new cancer cases and 9.6 million cancer deaths in 2018 [2].

Simvastatin is considered a good anti-dyslipidemic drug [3] which stops the cholesterol synthesis pathway (mevalonate pathway), and decreases the risk of atherosclerosis, stroke, coronary artery disease and ischemic heart diseases. It is found that simvastatin has antitumor properties against myeloma cells and induces cell cycle arrest at
G0/G1 and G2/M phases through mitochondrial pathway [4]. Green tea is a natural drink which enriched with polyphenols; the most important component of green tea polyphenol is epigallocatchen-3-gallate (EGCG). It has many healthy beneficial properties and is used for the primary prevention or alleviation of several chronic diseases including cancer, cardiac diseases, obesity, diabetes, neuro-degenerative diseases, and anti-infective effects [5, 6]. Radiotherapy is the most important regimen for cancer treatment where about $50 \%$ of cancer cases received radiotherapy sessions [7]. Gamma radiation is used, in suitable doses, to kill cancer cells in vitro and in vivo [8].

The magnetic resonance imaging (MRI) is considered one of the noninvasive imaging methods in radiology for diagnosis to detect the soft organs size, shape and homogeneity [9]. MRI

Corresponding author: ebtalah@gmail.com

DOI: 10.21608 /ajnsa.2020.22827.1322

(C) Scientific Information, Documentation and Publishing Office (SIDPO)-EAEA 
safety and quality of imaging was confirmed in diagnosis of the pediatric and adult patients with congenital heart disease [10], and oncology diagnosis [11] in different types of cancer: for examples, breast cancer [12], cervical cancer [13], lung cancer [14] and prostate cancer [15]. Using MRI during the experimental trial on animal models supports the researchers with all data about localization or metastasis of cancer whether about the solid or ascites tumor. Moreover, it supports follow of animal's prognosis on the long term with more details about the soft organs without dissection and sacrificing the animals.

In the present study, two main goals were adopted to explore the effect of EGCG, simvastatin and gamma radiation individually or combined together on Ehrlich solid tumor of mice. The second is to find a method of diagnosing and following up the treatment effect on the tumor bearing mice before, during and after treatment using the magnetic resonance imaging (MRI) without sacrificing the experimental animals.

\section{Material and method}

Materials

Simvastatin was purchased from Sharon BioMedicine LTD., Navi Mumbai, India. EGCG was purchased from Santa Cruz Biotechnology, European Support Office, Heidelberg, Germany. All tissue culture reagents were purchased from Sigma Company, Cairo, Egypt.

\section{Irradiation facilities}

Gamma cell 40 Unit ( $\mathrm{Cs}^{137}$, Gy=150 Second) is located at the National Center for Radiation Research and Technology (NCRRT), the Egyptian Atomic Energy Authority, Cairo, Egypt.

Ehrlich Ascites Carcinoma Cell Line (EAC) was obtained from the National Cancer Institute (NCI), Cairo University, Cairo, Egypt. Mice were injected subcutaneously in the right thigh with $250 \mu$ of Ehrlich tumor cell suspension in saline including cell viability more than $90 \%$ and total cell count of about $2-2.5 * 10^{6} / \mathrm{ml}$ for solid tumor induction and injected intraperitoneally for cells propagation and ascites induction.

\section{Animals}

Swiss albino mice of 6 weeks old (20-25g) were obtained from the NCRRT. Outbred females were used for ascites production and males for solid tumor induction in mice's femur. Animal care procedures were consistent with the guidelines of Ethics by Public Health Guide for the Care and Use of Laboratory Animals (National Research Council, 1996) in accordance with the recommendations for the proper care and use of laboratory animals.

Magnetic resonance imaging of ascites bearing mice

The mouse bearing ascites was anesthetized in a pre-warmed induction chamber using Thiopental sodium $\quad(50 \mathrm{mg} / \mathrm{kg})$ plus Atropine $(50 \mu \mathrm{gm} / \mathrm{kg})$, mice were fully anesthetized when they fail to respond to paw pinch. The duration scan was approximately 5 minutes. The details and device conditions were as follows: High resolution fast spin echo with time of repetition (TR) of $1930 \mathrm{~ms}$ and time of echo (TE) of $87 \mathrm{~ms}$. flip angle, 900; echo train length, 8; field of view, $4.4 \mathrm{~cm}$; section thickness, $2 \mathrm{~mm}$, 30 slices; Distance factor $30 \%$, FoV read, $190 \mathrm{~mm}$, FoV Phase $81.3 \%$. The MR images were acquired either perpendicular to the anterior-posterior long axis of the animal coronal or parallel to the anterior-posterior direction (axially) or sagittal from upward to downward to determine the width of the ascetic fluid intraperitoneally [16].

\section{Animal treatment}

Seventy two mice were divided into six groups $(n=12)$, the first group was a control, the rest of the animals (5 groups) were injected with EC cells in right thigh to form solid tumor. the first group was positive control, the second was treated with simvastatin $(15 \mathrm{mg} / \mathrm{kg} /$ body weight/day) [17], the third was treated with EGCG $(50 \mathrm{mg} / \mathrm{kg} /$ body weight/day) [18], the fourth group was treated with gamma radiation on three sessions each session $2 \mathrm{~Gy} /$ mice, and the fifth groupwas treated with triple therapy (Simvastatin, EGCG and Gamma radiation).

\section{Tumor size}

The measurement of tumor size of all groups was started at the beginning of pulp appearance in the positive control mice until it reached around 500:600 $\mathrm{mm}^{3}$. The size of solid tumor $\left(\mathrm{mm}^{3}\right)$ was measured according to the equation $\mathrm{V}=(\mathrm{W} 2 \times \mathrm{L}) / 2$ for caliper measurements, where $\mathrm{V}$ is the tumor volume, $\mathrm{W}$ is the tumor width (Minor tumor axis), $\mathrm{L}$ is the tumor length (Major tumor axis) [19]. 
Assessment of MST, ILS\%, T/C\% and TIR\%

Each group was monitored by recording the daily mortality. The end point of the experiment was determined by the spontaneous death of animals and the mean survival time (MST) was calculated according to the equation: $\mathrm{MST}=($ day of first death + day of last death)/2. The percentage increase in life span (ILS) was calculated using the equation $(\mathrm{ILS} \%=(\mathrm{T}-\mathrm{C}) / \mathrm{C} \times 100)$, where $\mathrm{T}$ represents MST of the treated animals and $\mathrm{C}$ represents MST of the control group. T/C\% (treated vs. EAC control) was calculated as MST of the treated animals/MST of the control group. TIR\% (tumor-growth inhibition rate $)=(\mathrm{C}-\mathrm{T}) / \mathrm{C} \times 100$, where $\mathrm{T}$ represents mean tumor volume of treated group and $\mathrm{C}$ represents the mean tumor volume of the control group. According to the criteria of the National Cancer Institute (NCI), T/C exceeding $125 \%$ and ILS exceeding $25 \%$ indicate that the drug has a significant anti-tumor activity [20-22].

\section{Statistical analysis}

All results were analyzed using the Statistical Package for the Social Sciences (SPSS) program, version 22. The survival rate and risk factor analysis were performed by survival analysis Kaplan Meier equation with its functions for PLOT SURVIVAL HAZARD LOGSURV. For comparison between tumor sizes, the split file equation was used to be compared through twoway ANOVA. All chart graphs were drawn using GraphPad Prisme version 6, except for survival rate and hazards functions, they were conducted using SPSS.

\section{Results}

\section{Tumor size}

Solid tumor was propagated by direct intramuscular injection with EC cells in the thigh. Tumor size changed through 8 days before treatment and reached $579.2 \mathrm{~mm}^{3}$. The positive control group was left without treatment for additional 16 days which is the period of treatment protocol for other groups as shown in Figure (1) where it reached $825 \pm 21.8 \mathrm{~mm}^{3}$ at day 24 of intramuscular injection (Day 16 of starting treatment protocol for other groups). The rest of the animals were classified according to the type of treatment regimen. The tumor size has changed according to the treatment regimen; it was measured with Verner caliper as shown in Figure
(2). The change of tumor size in all groups under study was calculated (Table1) and presented in Figure (3). In the positive control, tumor size reached its high peak after16 days and recorded $825 \pm 21.8 \mathrm{~mm}^{3}$, but in the case of combination therapy, the tumor size did not exceed $662 \pm 12.5 \mathrm{~mm}^{3}$. There was no significant difference in the rate of tumor size growth till the $8^{\text {th }}$ day of treatment protocol in all groups, however, in the $11^{\text {th }}$ day a significant difference occured in the simvastatin group $(P$ value $=0.025)$ and the combination therapy groups $(P$ value $=0.007)$ compared to the positive control group. There was no significant difference in radiation and EGCG groups. At $14^{\text {th }}$ and $16^{\text {th }}$ days, the tumor size had a significant difference in the simvastatin, EGCG and combination therapy groups compared to the positive control group

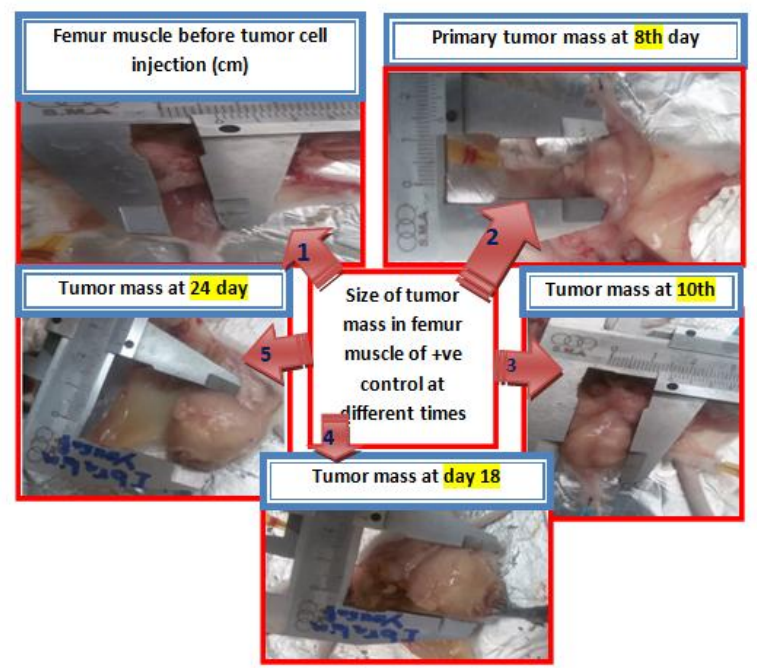

Figure (1): The changes in the size of solid tumor growth in positive control group through 24 days after intramuscular EC cells injection

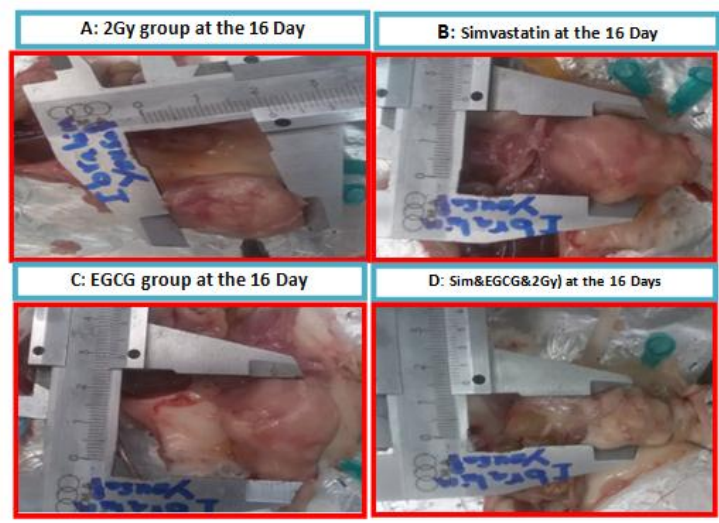

Figure (2, A- D): The changes in the solid tumor mass size with caliper at the end of experiment under different regimens of treatment 


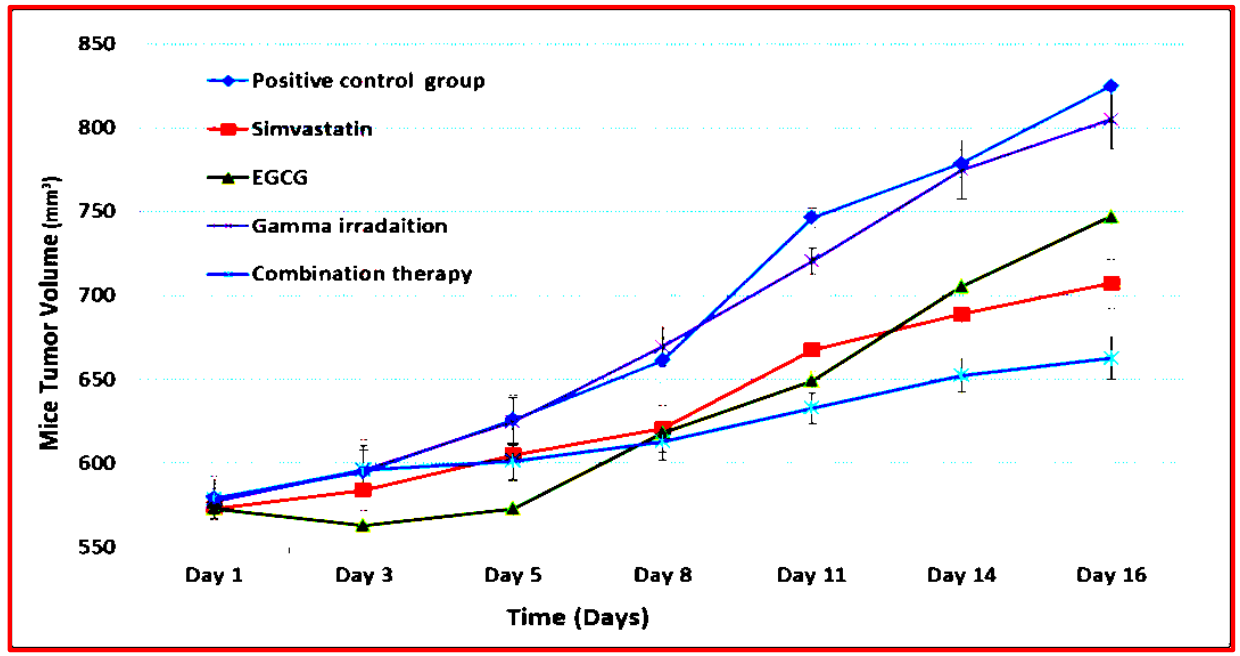

Figure (3): The change in the solid tumor volume $\left(\mathrm{mm}^{3}\right)$ through 16 Days of treatment in different groups with different regimens of treatment

Table (1): Changes of solid tumor volume $\left(\mathrm{mm}^{3}\right)$ in different groups of animals through 16 days with the valid number of cases $(N)$ for each day

\begin{tabular}{l|l|l|l|l|l|l|l|l|l|l|l|l|l|l|l|l|l|l|l|l|l}
\hline \multicolumn{1}{c|}{ Days } & \multicolumn{3}{|c|}{ Positive control } & \multicolumn{3}{c|}{ Simvastatin } & \multicolumn{3}{c|}{ EGCG } & \multicolumn{3}{c|}{ Gamma irradaition } & \multicolumn{3}{c}{ Combination therapy } \\
\hline & Mean & \pm & SE & N & Mean & \pm & SE & N & Mean & \pm & SE & N & Mean & \pm & SE & N & Mean & \pm & SE & N \\
Day 1 & 579.2 & \pm & 12.97 & 12 & 572.8 & \pm & 14.7 & 12 & 572.8 & \pm & 14.7 & 12 & 577.0 & \pm & 7.9 & 12 & 578.7 & \pm & 11.2 & 12 \\
Day 3 & 594.6 & \pm & 19.5 & 11 & 583.9 & \pm & 11.8 & 12 & 563.0 & \pm & 15.3 & 11 & 596.2 & \pm & 14.4 & 11 & 595.8 & \pm & 11.8 & 11 \\
Day 5 & 626.1 & \pm & 14.5 & 10 & 605.0 & \pm & 15.6 & 10 & 572.8 & \pm & 14.4 & 10 & 624.7 & \pm & 13.9 & 10 & 601.3 & \pm & 10.6 & 11 \\
Day 8 & 661.2 & \pm & 13.3 & 7 & 620.7 & \pm & 14.1 & 9 & 618.2 & \pm & 13.7 & 8 & 669.3 & \pm & 11.5 & 9 & 612.8 & \pm & 11.0 & 10 \\
Day 11 & 746.5 & \pm & 5.8 & 7 & 667.7 & \pm & 12.9 & 9 & 649.1 & \pm & 7.3 & 8 & 720.7 & \pm & 7.8 & 8 & 632.9 & \pm & 9.1 & 10 \\
Day 14 & 778.7 & \pm & 8.6 & 6 & 688.8 & \pm & 12.5 & 8 & 705.5 & \pm & 11.0 & 7 & 774.8 & \pm & 16.9 & 7 & 652.2 & \pm & 9.8 & 9 \\
Day 16 & 825.0 & \pm & 21.8 & 3 & 707.2 & \pm & 14.6 & 7 & 747.2 & \pm & 7.6 & 6 & 805.0 & \pm & 17.5 & 5 & 662.6 & \pm & 12.5 & 8 \\
\hline Valid N & \multicolumn{10}{|c|}{3} \\
\hline
\end{tabular}

Survival rate analysis

The survival rate in response to various types of treatments, single or combined, was evaluated with Kaplan-Meier analysis. There is no significant difference between the untreated group and other types of treatment regarding the survival rate except the combination therapy. The survival rate has no significant difference with simvastatin $(P$ value $=0.152), \quad$ EGCG $\quad(P$ value $=0.332) \quad$ and Gamma irradiation $(P$ value $=0.469)$, but there was a significant difference compared to triple therapy
( $P$ value $=0.054)$ over 16 days of treatment. The rate of death reached to $75 \%, 41.7 \%, 50 \%, 58.3 \%$ and $33.3 \%$ in different protocols; positive control, simvastatin, EGCG, Gamma irradiation and triple therapy, respectively. The combination therapy was more potent than single therapies, where it increased the survival rate to $66.7 \%$ compared with $25 \%$ untreated control, as shown in Table (2) and illustrated in Figs. $(4 \& 5)$ that show the survival rate curve and hazard curve. 
ANTI-TUMOR EFFECT OF GREEN TEA EXTRACT....

Table (2): The survival rate in different groups of animals through 16 days

\begin{tabular}{|c|c|c|c|c|c|c|c|c|c|c|c|c|c|c|}
\hline \multicolumn{3}{|c|}{ Positive control } & \multicolumn{3}{|c|}{ Simvastatin } & \multicolumn{3}{|c|}{ EGCG } & \multicolumn{3}{|c|}{ Gamma Irradiation } & \multicolumn{3}{|c|}{ Combination Therapy } \\
\hline $\begin{array}{l}\text { Time } \\
\text { (Days) }\end{array}$ & $\begin{array}{l}\text { Statu } \\
\mathrm{s}\end{array}$ & $\begin{array}{c}\mathrm{N} \text { of } \\
\text { Cum. } \\
\text { Even } \\
\text { ts }\end{array}$ & $\begin{array}{c}\text { Time } \\
\text { (Day } \\
\text { s) }\end{array}$ & $\begin{array}{l}\text { Statu } \\
\mathrm{s}\end{array}$ & $\begin{array}{l}\mathrm{N} \text { of } \\
\text { Cum. } \\
\text { Even } \\
\text { ts }\end{array}$ & $\begin{array}{c}\text { Time } \\
\text { (Day } \\
\text { s) }\end{array}$ & $\begin{array}{l}\text { Statu } \\
\mathrm{s}\end{array}$ & $\begin{array}{c}\mathrm{N} \text { of } \\
\text { Cum. } \\
\text { Even } \\
\text { ts }\end{array}$ & $\begin{array}{c}\text { Time } \\
\text { (Day } \\
\text { s) }\end{array}$ & $\begin{array}{l}\text { Statu } \\
\mathrm{s}\end{array}$ & $\begin{array}{l}\mathrm{N} \text { of } \\
\text { Cum. } \\
\text { Even } \\
\text { ts }\end{array}$ & $\begin{array}{c}\text { Time } \\
\text { (Day } \\
\text { s) }\end{array}$ & $\begin{array}{l}\text { Statu } \\
\mathrm{S}\end{array}$ & $\begin{array}{c}\mathrm{N} \text { of } \\
\text { Cum. } \\
\text { Even } \\
\text { ts }\end{array}$ \\
\hline 1 & Die & 1 & 2 & Die & 1 & 1 & Die & 1 & 1 & Die & 1 & 2 & Die & 1 \\
\hline 2 & Die & 2 & 2 & Die & 2 & 2 & Die & 2 & 2 & Die & 2 & 4 & Die & 2 \\
\hline 4 & Die & 3 & 4 & Die & 3 & 4 & Die & 3 & 4 & Die & 3 & 9 & Die & 3 \\
\hline 4 & Die & 4 & 9 & Die & 4 & 4 & Die & 4 & 7 & Die & 4 & 11 & Die & 4 \\
\hline 4 & Die & 5 & 11 & Die & 5 & 9 & Die & 5 & 9 & Die & 5 & 15 & alive & 4 \\
\hline 9 & Die & 6 & 15 & alive & 5 & 11 & Die & 6 & 11 & Die & 6 & 15 & alive & 4 \\
\hline 11 & Die & 7 & 15 & alive & 5 & 15 & alive & 6 & 11 & Die & 7 & 15 & alive & 4 \\
\hline 11 & Die & 8 & 15 & alive & 5 & 15 & alive & 6 & 15 & alive & 7 & 15 & alive & 4 \\
\hline 11 & Die & 9 & 15 & alive & 5 & 15 & alive & 6 & 15 & alive & 7 & 15 & alive & 4 \\
\hline 15 & alive & 9 & 15 & alive & 5 & 15 & alive & 6 & 15 & alive & 7 & 15 & alive & 4 \\
\hline 15 & alive & 9 & 15 & alive & 5 & 15 & alive & 6 & 15 & alive & 7 & 15 & alive & 4 \\
\hline 15 & alive & 9 & 15 & alive & 5 & 15 & alive & 6 & 15 & alive & 7 & 15 & alive & 4 \\
\hline$\%$ of Death & \multicolumn{2}{|c|}{$75 \%$} & \multicolumn{3}{|c|}{$41.7 \%$} & \multicolumn{3}{|c|}{$50 \%$} & \multicolumn{3}{|c|}{$58.3 \%$} & \multicolumn{3}{|c|}{$33.3 \%$} \\
\hline $\begin{array}{l}\% \text { of } \\
\text { Censored }\end{array}$ & \multicolumn{2}{|c|}{$25 \%$} & \multicolumn{3}{|c|}{$58.30 \%$} & \multicolumn{3}{|c|}{$50 \%$} & \multicolumn{3}{|c|}{$41.71 \%$} & \multicolumn{3}{|c|}{$66.70 \%$} \\
\hline
\end{tabular}

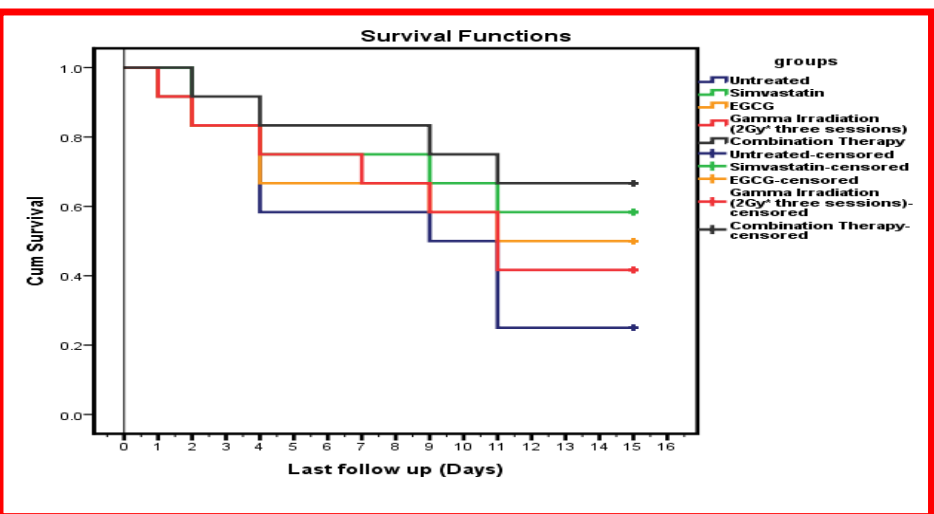

Figure (4): The Kaplan-Meier mouse survival curves analysis for four different protocols of treatment (n=12), significance is only detected in combination therapy protocol $(P$ value $=\mathbf{0 . 0 5 4})$

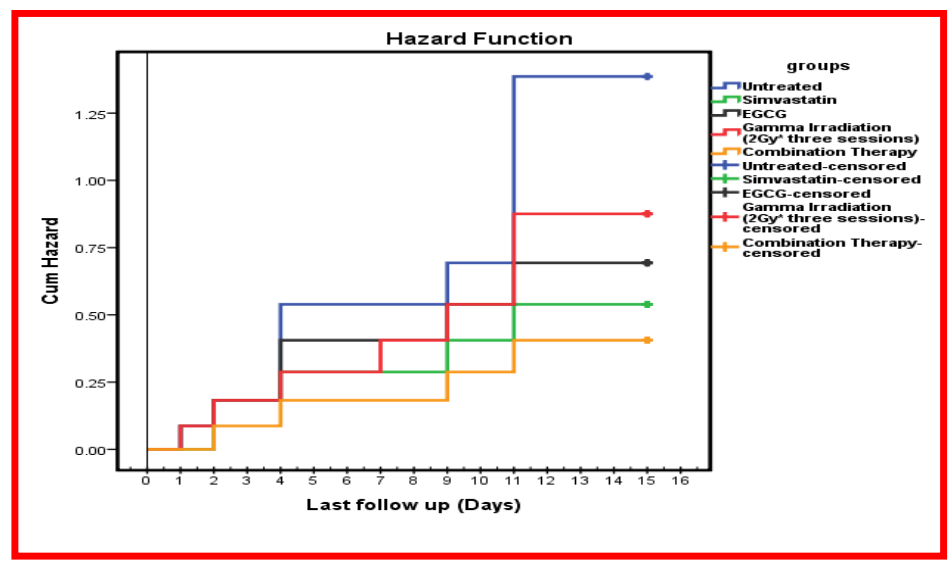

Figure (5): The Kaplan-Meier mouse plot of the hazard rate for animals having EC cells as solid tumor in groups of animals treated with different protocols 
Assessment of MST, ILS\%, T/C\% and TIR\%

Each group of animals was monitored to calculate the tumor size and survival rate, also daily deaths were recorded. Moreover each of MST, ILS, T/C and TIR\% was calculated as shown in Table (3) where the triple therapy of simvastatin, EGCG and Gamma radiation achieved the best results and recorded the best value of $\mathrm{T} / \mathrm{c}=142$ and ILS $=42.11$. Therefore, it is approved primary and considered as anti-tumor activity according to the National Cancer Institute criteria. The single regimen of treatment of simvastatin and EGCG recorded results of ILS\% (31.58 and 26.32, respectively) and T/C (132 and 126, respectively).
Change in animals' weight in different groups under study

Mice weights were changed a cross the time of experiment (16 days) as shown in Table (4) and Figure (5). There is no significant difference through the first 5 days of experiment after that, a significant difference started to appear from the $8^{\text {th }}$ day where there was a significant difference between the positive control group and other different groups; simvastatin, EGCG, gamma irradiation and combination therapy where the $P$ values were $<0.01,<0.01,0.003$ and $<0.01$, respectively.

Table (3): MST, ILS\%, TIR\% and T/C

\begin{tabular}{|c|c|c|c|c|c|c|c|}
\hline \multirow[b]{2}{*}{ Group } & \multicolumn{3}{|c|}{ MST parameters } & \multirow[b]{2}{*}{ ILS\% } & \multirow{2}{*}{$\begin{array}{l}\text { Mean tumor volume } \\
\qquad\left(\mathrm{mm}^{3}\right)\end{array}$} & \multirow[b]{2}{*}{ TIR\% } & \multirow[b]{2}{*}{$\mathrm{T} / \mathrm{C}$} \\
\hline & First death day & Last death day & MST & & & & \\
\hline Positive Control & 2 & 17 & 9.5 & 0 & 825 & & 100 \\
\hline Simvastatin & 3 & 22 & 12.5 & 31.58 & 707.2 & 14.28 & 132 \\
\hline EGCG & 2 & 22 & 12 & 26.32 & 747.2 & 9.43 & 126 \\
\hline Gamma Rad. & 2 & 21 & 11.5 & 21.05 & 805.0 & 2.42 & 121 \\
\hline Triple therapy & 2 & 25 & 13.5 & 42.11 & 662.6 & 19.68 & 142 \\
\hline
\end{tabular}

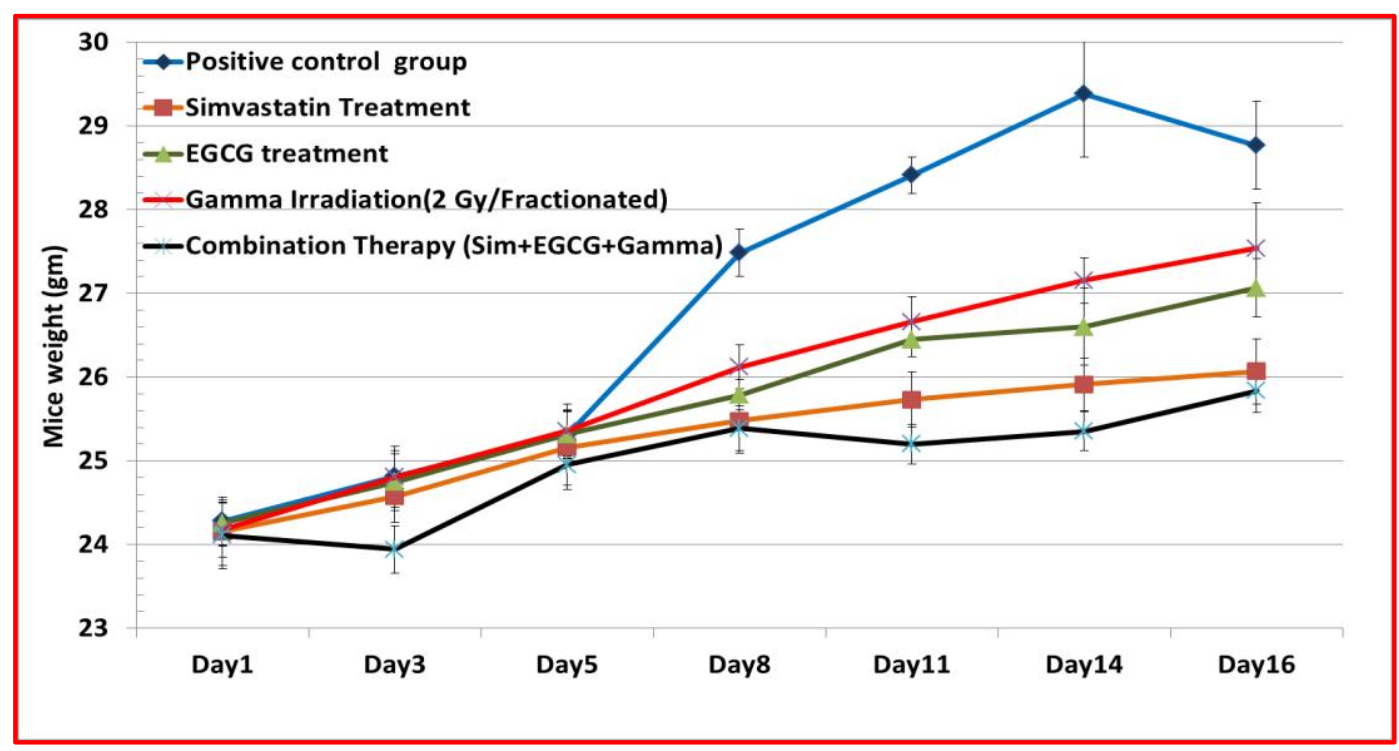

Figure (5): The changes in the weight of mice (grams) under study in different groups through 16 days after treatment 
Table (4): Mean of weight changes in different groups of animals through 16 days of treatment

\begin{tabular}{|c|c|c|c|c|c|}
\hline \multicolumn{2}{|l|}{ Groups } & $\mathrm{N}$ & Mean & SE & SD \\
\hline \multirow{7}{*}{ Positive control } & Day 1 & 12 & 24.28 & 0.29 & 1 \\
\hline & Day 3 & 11 & 24.82 & 0.31 & 1.01 \\
\hline & Day 5 & 10 & 25.31 & 0.29 & 0.9 \\
\hline & Day 8 & 7 & 27.49 & 0.28 & 0.75 \\
\hline & Day 11 & 7 & 28.41 & 0.22 & 0.58 \\
\hline & Day 14 & 6 & 29.38 & 0.75 & 1.84 \\
\hline & Day 16 & 3 & 28.77 & 0.52 & 0.91 \\
\hline \multirow{7}{*}{ Simvastatin } & Day 1 & 12 & 24.16 & 0.41 & 1.42 \\
\hline & Day 3 & 12 & 24.58 & 0.31 & 1.06 \\
\hline & Day 5 & 10 & 25.16 & 0.45 & 1.42 \\
\hline & Day 8 & 9 & 25.48 & 0.39 & 1.16 \\
\hline & Day 11 & 9 & 25.73 & 0.33 & 0.99 \\
\hline & Day 14 & 8 & 25.91 & 0.32 & 0.89 \\
\hline & Day 16 & 7 & 26.07 & 0.39 & 1.03 \\
\hline \multirow{7}{*}{ EGCG } & Day 1 & 12 & 24.26 & 0.28 & 0.96 \\
\hline & Day 3 & 11 & 24.75 & 0.34 & 1.12 \\
\hline & Day 5 & 10 & 25.32 & 0.26 & 0.84 \\
\hline & Day 8 & 8 & 25.79 & 0.18 & 0.52 \\
\hline & Day 11 & 8 & 26.45 & 0.21 & 0.58 \\
\hline & Day 14 & 7 & 26.6 & 0.46 & 1.22 \\
\hline & Day 16 & 6 & 27.07 & 0.35 & 0.85 \\
\hline \multirow{7}{*}{$\begin{array}{l}\text { Gamma Irradiation(2 } \\
\text { Gy/Fractionated) }\end{array}$} & Day 1 & 12 & 24.18 & 0.33 & 1.13 \\
\hline & Day 3 & 11 & 24.81 & 0.37 & 1.22 \\
\hline & Day 5 & 10 & 25.36 & 0.32 & 1.02 \\
\hline & Day 8 & 9 & 26.12 & 0.26 & 0.79 \\
\hline & Day 11 & 8 & 26.66 & 0.3 & 0.84 \\
\hline & Day 14 & 7 & 27.16 & 0.27 & 0.73 \\
\hline & Day 16 & 5 & 27.54 & 0.54 & 1.22 \\
\hline \multirow{7}{*}{$\begin{array}{c}\text { Combination Therapy (Sim+ } \\
\text { EGCG+Gamma) }\end{array}$} & Day 1 & 12 & 24.11 & 0.4 & 1.38 \\
\hline & Day 3 & 12 & 23.94 & 0.29 & 0.99 \\
\hline & Day 5 & 11 & 24.95 & 0.3 & 0.99 \\
\hline & Day 8 & 10 & 25.39 & 0.27 & 0.85 \\
\hline & Day 11 & 10 & 25.2 & 0.24 & 0.74 \\
\hline & Day 14 & 9 & 25.36 & 0.24 & 0.71 \\
\hline & Day 16 & 8 & 25.84 & 0.26 & 0.74 \\
\hline
\end{tabular}




\section{Morphological changes of tumor area}

Different morphological changes the tumor area of the thigh of the treated animals were recorded. Animals of the positive control group showed a high level of inflammation in tumor area caused gangrene which consequently led to the loss of the hind limb at day 14 Figure (7A). Peripheral artery disease / critical limb ischemia (PAD/CLI) is an ischemic condition that is typically caused by reduced tissue perfusion secondary to blocked or partially blocked arteries Figure (7B-E). The triple therapy was the lowest rate of ischemia and inflammation. EGCG was a moderate case of ischemia with the symptoms of ischemia and inflammation in tumor area and hind limb.

\section{Magnetic resonance imaging}

Ehrlich carcinoma cells were propagated as ascites in the female Swiss albino mice after one shot intraperitoneal (ip) inoculation of 2-2.5×106 cells (suspended in saline). The ascites was formed
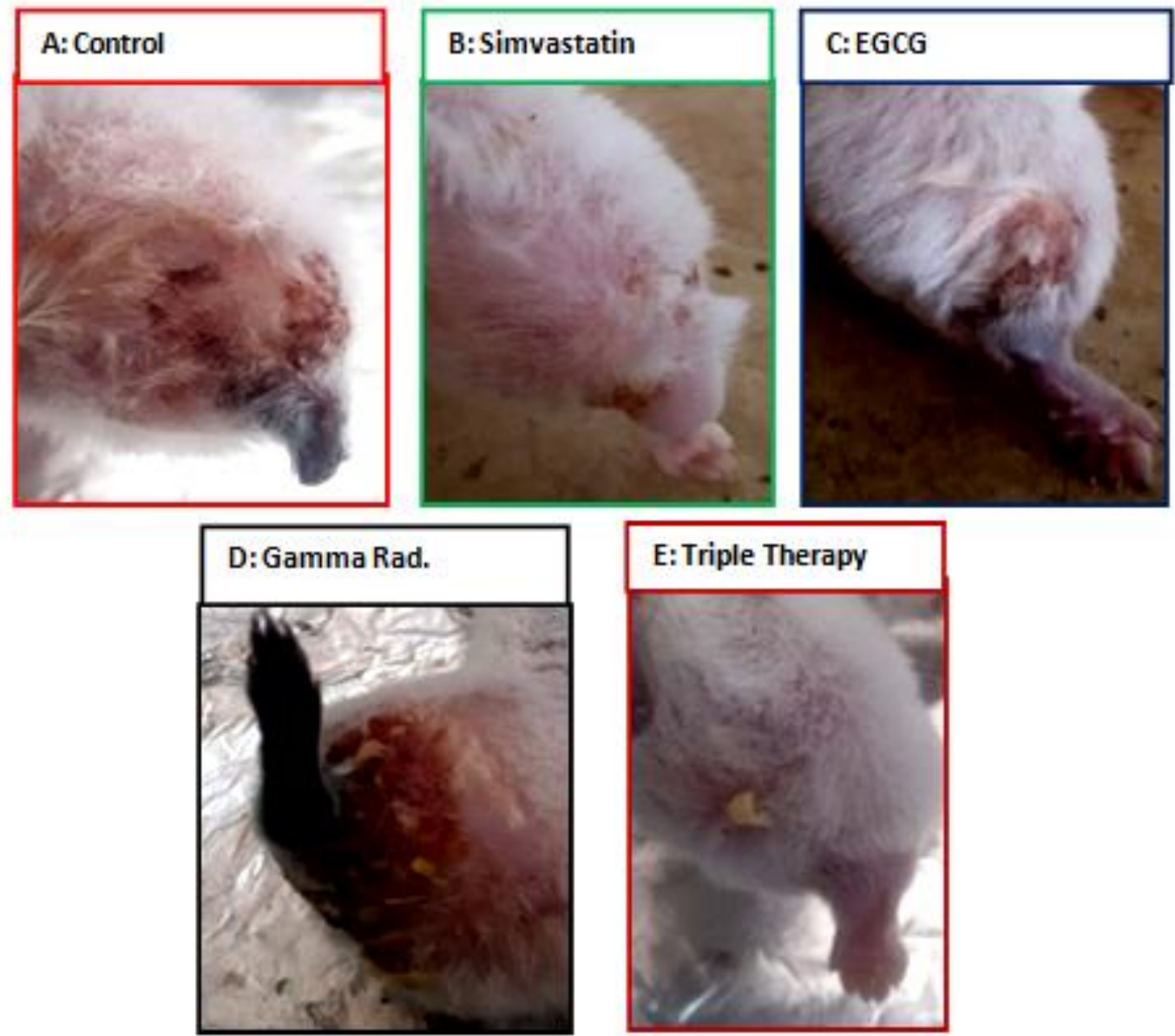

Figure (7, A- E): Morphological changes in the tumor areas regarding to inflammations, hair loss and level of gangrene due to changes in the rate of blood supply through PAD/CLI 

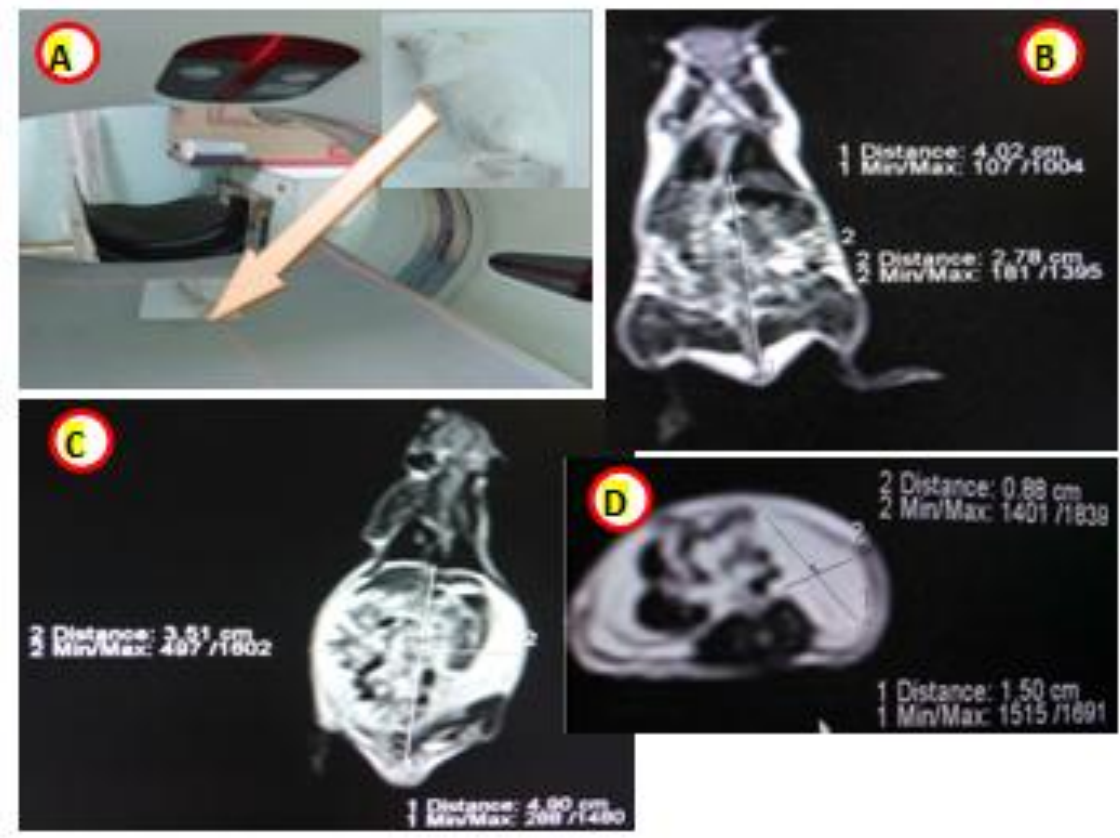

Figure (8): The MRI for mice under study, A: mouse on device table and under the field of radiation, B: Show the coronal plane sections for normal mouse without any ascites, C: The coronal plane section with ascetic fluid with its distances, and D: the transverse plane sections with ascetic fluid measurements

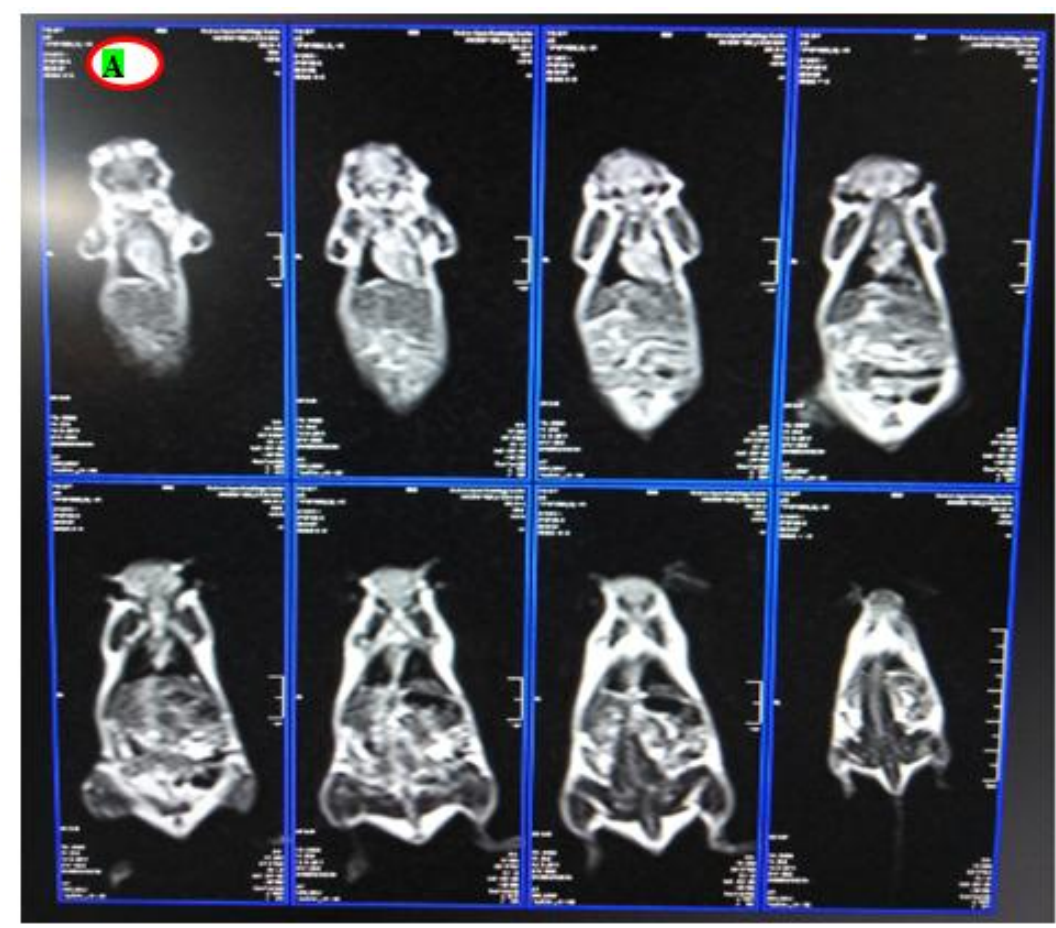

(A) 


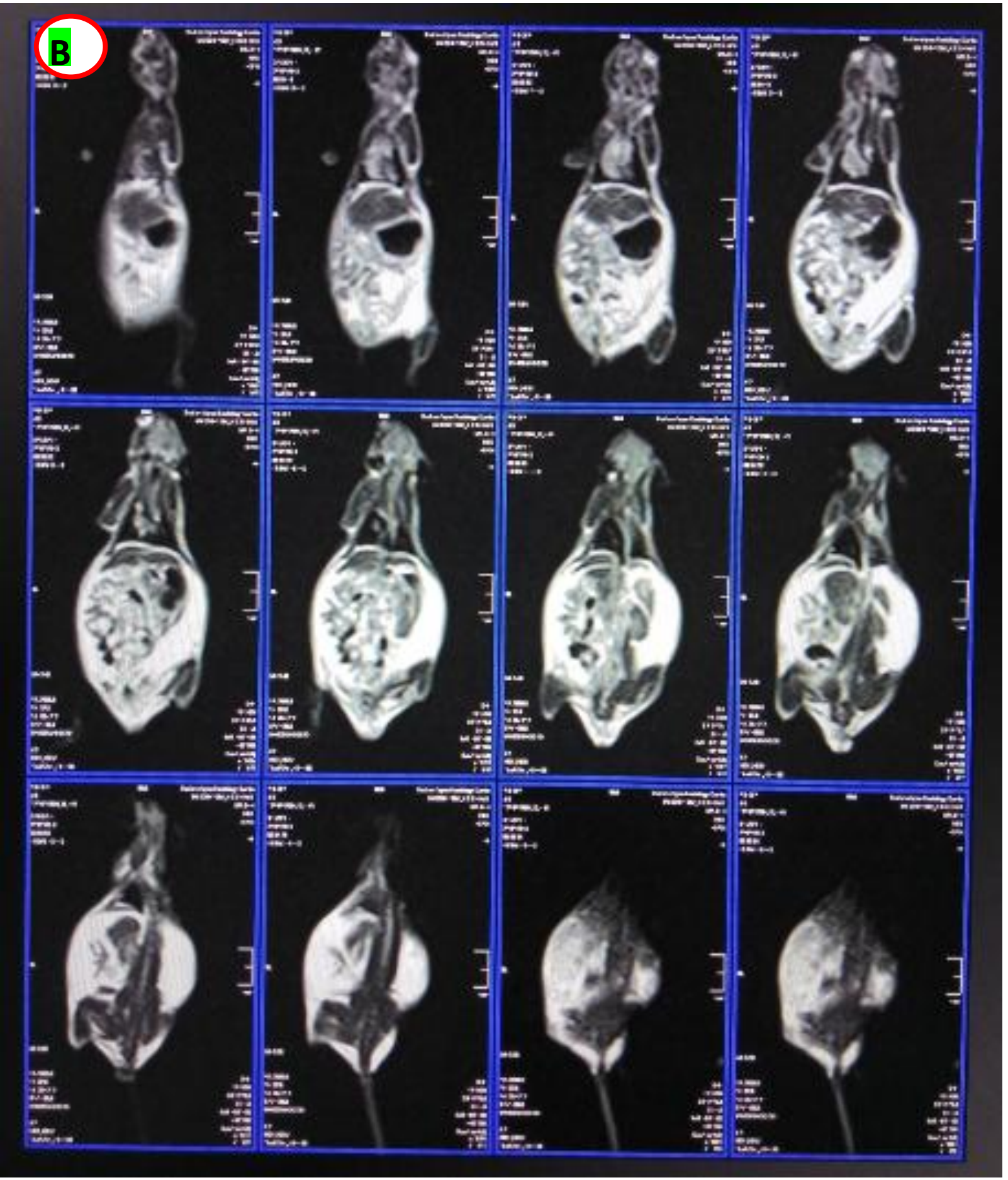

(B)

Figure (9) The whole body MRI sections, (A): represent the coronal plane section for normal control mice, (B): represent the different coronal plane section of mice bearing ascites. 


\section{Discussion}

Diagnosis is a very important facility for early cancer detection and an excellent tool for prognosis and patient follow-up. In the current study, the MR imaging was used to detect the ascetic fluid to evaluate its volume, places and the impact of cancer on different soft organs without killing the experimental animals. The target of using MRI was to determine the changes on the following organs: liver, kidney, spleen, Lung, brain and GIT in addition to its follow-up during treatment. In current study, the MRI device strength 1.5 Tesla (T) magnets was used. The results were obtained from MRI scanners under using the following conditions: high resolution fast spin echo with repetition time $\mathrm{TR}=1930 \mathrm{~ms}$, TE $=87 \mathrm{~ms}$, flip angle, 900; echo train length, 8; field of view, $4.4 \mathrm{~cm}$; section thickness, $2 \mathrm{~mm}, 30$ slices; Distance factor 30\%, FoV read, 190mm, FoV Phase $81.3 \%$. The obtained images were very good in visualizing ascites intraperitoneal and evaluating its volume and its distribution in general visceral. Most of the visceral organs were bright in case of ascites bearing mice, but they did not look good in normal mice. In MRI, paracolic gutter was examined, these gutters are clinically important because they allow a passage for infectious or tumor ascites fluids from different compartments of the abdomen. For example; injected ascites from intraperitoneal can track up the right paracolic gutter to the hepatorenal recess. There are some limitation during this study using MRI, as the small size of the animal within the MRI magnet revealing less details and using large FOV gives less detailed image. Thus using the smaller FOV which leads to the higher resolution and the smaller voxel size is recommended, but the lower measured signal, in addition, the high strength of MRI device could be used to detect more details about soft organs of mice's body.

EGCG as anticancer, it was used for solid tumor in the right thigh of the mice in late stage of tumor formation, the current results approved that the usage of EGCG $(50 \mathrm{mg} / \mathrm{kg})$ can increase survival rate of tumor bearing mice to $50 \%$ versus $25 \%$ of the control, in addition to decreasing the inflammation in the tumor area compared to control; which is the reliable factor assuring the antitumor properties of EGCG. EGCG not only induces the prolongation of lifespan and attenuate inflammation, but it also decreases significantly the tumor size after 16 days of treatment (747.1 $\mathrm{mm}^{3} \mathrm{vs} .825 \mathrm{~mm}^{3}$ in the control, Pvalue=0.01) compared to the control. These findings regarding to antitumor effect of EGCG on animal model agreed with the findings on Murine WEHI-3generated leukemic BALB/c mice where EGCG were used orally at a dose of $40 \mathrm{mg} / \mathrm{kg}$ in olive oil and they suggested that the EGCG promotes the immune response through increasing the levels of T-cell and macrophage cell surface markers [23] and on solid tumor of A549 cells in front dorsum of mice [24]. According to the criteria of the National Cancer Institute, if T/C exceeding $125 \%$ and ILS exceeding $25 \%$ indicate that the drug has a significant anti-tumor activity [20, 22]. Different treatments in the current study either single or combined achieved this criterion except single treatment with gamma radiation (6Gy fractionated in three sessions). The triple therapy of Simvastatin, EGCG and Gamma radiation achieved the best results and recorded the best value of $\mathrm{T} / \mathrm{c}=142$ and ILS=42.11. Hence, it should be approved primary and considered as an antitumor regimen. The single treatment of simvastatin and EGCG showed good results of ILS\% (31.58 and 26.32, respectively) and T/C (132 and 126, respectively) as shown in Table (3).

Regarding the current results in vivo through studying the effect of simvastatin on solid tumor of the right thigh of the mice in late stage of tumor formation, its approved that the usage of simvastatin $(15 \mathrm{mg} / \mathrm{kg})$ as anticancer increased the survival rate of tumor bearing mice to $58.3 \%$ versus $25 \%$ of the control which agreed with its effect on the survival rate of gastrointestinal cancer in human patient [25]. It is recorded that the tumor size significantly decreased after 16 days of treatment $\left(707 \mathrm{~mm}^{3}\right.$ vs. $825 \mathrm{~mm}^{3}$ in control, $P$ value $=0.01)$ compared to the control. These findings approved antitumor effect of simvastatin on solid tumor animal model and agreed with the finding on a rat model of malignant glioma [26] and breast cancer in the mice [27]. Simvastatin recorded good results of ILS\% (31.58), T/C (132) and TIR\% is $14.28 \%$. Moreover, the obtained data confirmed the antitumor efficacy of simvastatin regarding some types of cancer which agreed with the studies of [28]. 
Gamma radiation has a slight effects on the solid tumor area of treatment, and the fractionated doses of gamma radiation (6Gy fractionated), but it was nonsignificant where the tumor size recorded $805 \pm 17.4 \mathrm{~mm}^{3}$ in comparison to $825 \pm 21.8 \mathrm{~mm}^{3}$ in untreated control, $P$ value $=0.824$ and it increased the survival rate to $41.7 \%$ compared to $25 \%$ in the untreated control, which confirmed the weak effect of $6 \mathrm{~Gy}$ in vivo when it fractionated on three session and ILS\% recorded $21.05, \mathrm{~T} / \mathrm{C}$ recorded 121 and TIR\% was $2.42 \%$ those numbers confirm that this regimen cannot be used in vivo as an antitumor regimen according to the National Cancer Institute guidelines.

The effect of combination therapy between EGCG, simvastatin and gamma radiation as antitumor regimen is tested on the solid tumor in vivo. It reduced the tumor size significantly after 16 days of treatment where tumor size recorded was $662.6 \pm 12.5 \mathrm{~mm}^{3}$ in comparison to $825 \pm 21.8 \mathrm{~mm}^{3}$ in control (Pvalue <0.01) and it increase the survival rate to $66.7 \%$ in comparison to $25 \%$ of control in addition to its reduction of the inflammation of tumor area and prevent the gangrene incidence. In the groups of animals with different treatments with single EGCG, simvastatin and radiation or combined, the rate of ischemia differs according to the size of tumor and rate of inflammation caused due to atherosclerosismediated critical limb ischemia (CLI) which represents the most severe manifestation of peripheral artery disease (PAD) and the main cause of ischemic rest pain, non-healing ulcers, and gangrene or tissue loss. The triple therapy of simvastatin, EGCG and Gamma radiation achieved the best results and recorded the best value of $\mathrm{T} / \mathrm{c}=142$ and ILS=42.11 and TIR \%19.6. Thus, it has been approved primary, and considered as an anti-tumor regimen according to the National Cancer Institute.

Regarding the mechanism of action of each of EGCG, simvastatin and gamma radiation on reducing the aggressiveness of tumor including prostate and breast cancers, EGCG mechanism including antioxidant activity in addition to its role as a $20 \mathrm{~S}$ proteasome inhibitor, and increased the expression of pro-apoptotic proteins, such as I $\mathrm{KB}$ and Bax, both of which are NF- $\kappa \mathrm{B}$ inhibitors [29]. Simvastatin inhibits mevalonate pathway through inhibition of hydroxymethylglutaryl coA reductase enzyme which in turn stopes the cholesterol synthesis and coenzyme $\mathrm{Q}$ (ubiquinone), the last enzyme has an important role in tumor growth $[4$, 30].

\section{Conclusion}

Combination therapy of EGCG, simvastatin and Gamma radiation induced solid tumor reduction and decreased the rate of inflammatory in addition to increasing the survival rate more than single treatment of each drug. Moreover, the present study opens the door to use simvastatin and EGCG or green tea as a potent anti-inflammatory and anticancer agents with radiotherapy session for humans. Thus, further investigation is needed on a human model with different types of cancers as shown in Figure (10). 


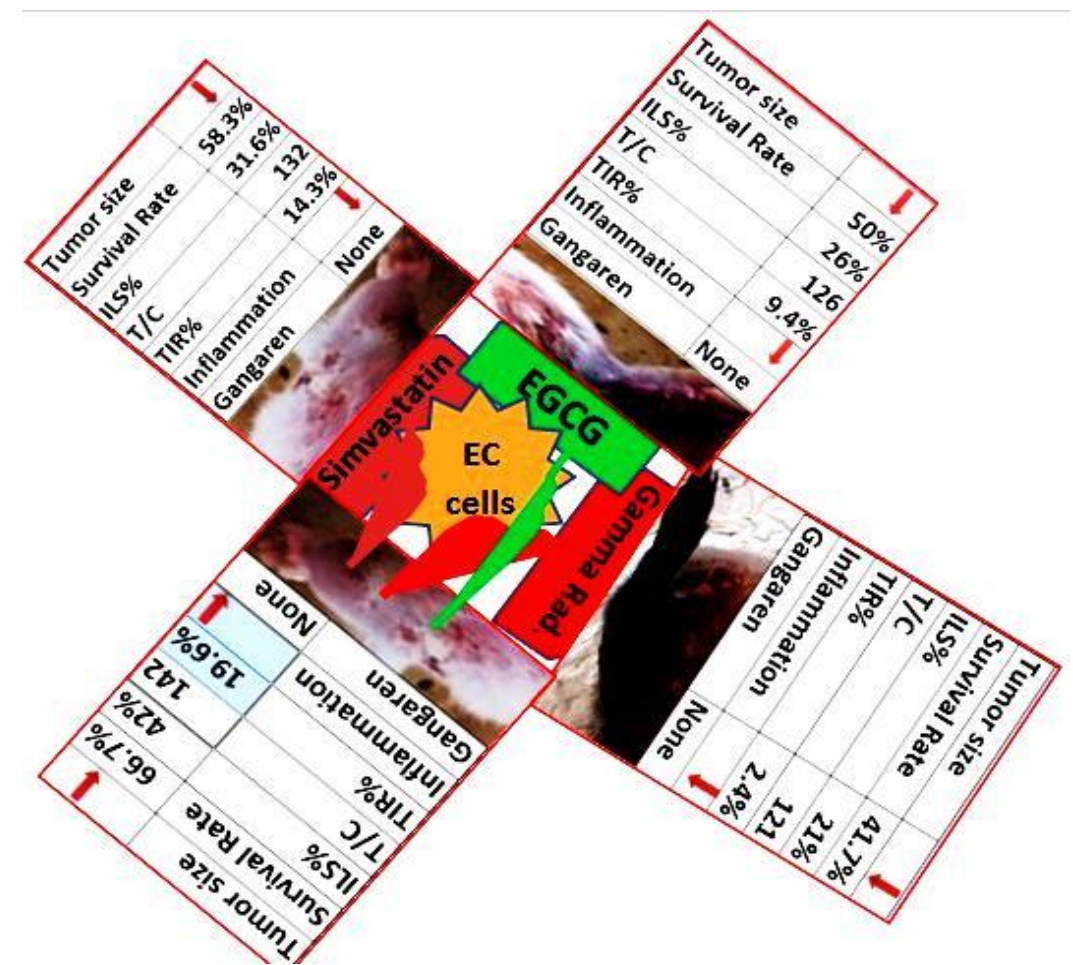

Figure (10): the antitumor properties of EGCG, Simvastatin and Gamma radiation or their combination

\section{Acknowledgements}

This work was carried out at the National Center for Radiation Research and technology, Animal house under supervision of Prof. Dr. Safwat Farid Salama, the supervisor of animal house. The MRI images were analyzed by Prof. Dr. Youssof Ahmed Y. Selem and Dr. Rady Mohamed Azoz

\section{References}

1-Alamgir, M., Global And Regional Cancer Epidemiology: According To World Cancer Report 2012 And Others. 2018.

2-Bray, F., et al., Global cancer statistics 2018: GLOBOCAN estimates of incidence and mortality worldwide for 36 cancers in 185 countries. CA: a cancer journal for clinicians, 2018. 68(6): p. 394-424.

3-Liu, X.-m., et al., Simvastatin improves olanzapineinduced dyslipidemia in rats through inhibiting hepatic mTOR signaling pathway. 2019: p. 1.

4-Abdelrahman, I., et al., Induction of P3NS1 Myeloma Cell Death and Cell Cycle Arrest by Simvastatin and/or $\gamma$-Radiation. Asian Pac J Cancer Prev.,, 2015. 16(16): p. 7103-7110.

5-Steinmann, J., et al., Anti-infective properties of epigallocatechin-3-gallate (EGCG), a component of green tea. British journal of pharmacology, 2013. 168(5): p. 1059-1073.
6-Bartosikova, L. and J. Necas, Epigallocatechin gallate: a review. Veterinární medicína, 2018. 63(10): p. 443-467.

7-Gelband, H., et al., Disease Control Priorities. Vol. 3. 2015, Cancer: The World Bank.

8-Coria-Domínguez, L., et al. Synergistic effect in vitro of ergosterol peroxide isolated from Pleurotus ostreatus in combination with Cesium-137 in cervical cancer cell line. in AIP Conference Proceedings. 2019. AIP Publishing.

9-Dolgushin, M., V. Kornienko, and I. Pronin, Magnetic Resonance Imaging (MRI), in Brain Metastases. 2018, Springer. p. 51-83.

10-Wang, L., et al., Use of magnetic resonance imaging combined with gene analysis for the diagnosis of fetal congenital heart disease. BMC medical imaging, 2019. 19(1): p. 12.

11-Petralia, G., et al., Whole-body magnetic resonance imaging (WB-MRI) in oncology: recommendations and key uses. La radiologia medica, 2019. 124(3): p. 218-233.

12-Gilbert, F.J. and K. Pinker-Domenig, Diagnosis and Staging of Breast Cancer: When and How to Use Mammography, Tomosynthesis, Ultrasound, Contrast-Enhanced Mammography, and Magnetic Resonance Imaging, in Diseases of the Chest, Breast, Heart and Vessels 2019-2022. 2019, Springer. p. 155-166.

13-Sghedoni, B., et al. Magnetic resonance of cervical cancer: relevance of T2-weighted imaging and 
apparent diffusion coefficient in predicting parametrial invasion. 2019. European Congress of Radiology 2019.

14-Francisco, V., et al. Computer-Aided Diagnosis of Lung Cancer in Magnetic Resonance Imaging Exams. in XXVI Brazilian Congress on Biomedical Engineering. 2019. Springer.

15-Yu, M., et al., MP33-10 INCREASING UTILIZATION OF MULTI-PARAMETRIC MAGNETIC RESONANCE IMAGING IN PROSTATE CANCER ACTIVE SURVEILLANCE. The Journal of Urology, 2019. 201(Supplement 4): p. e456-e456.

16-Cho, K.-H., et al., Development, integration and use of an ultra-high-strength gradient system on a human-size 3 T magnet for small animal MRI. PloS one, 2019. 14(6): p. e0217916.

17-Sondergaard, T., et al., A phase II clinical trial does not show that high dose simvastatin has beneficial effect on markers of bone turnover in multiple myeloma. 2009. 27(1): p. 17-22.

18-Li, N., et al., Herceptin-conjugated liposomes coloaded with doxorubicin and simvastatin in targeted prostate cancer therapy. 2019. 11(3): p. 1255.

19-Faustino-Rocha, A., et al., Estimation of rat mammary tumor volume using caliper and ultrasonography measurements. Lab animal, 2013. 42(6): p. 217.

20-Plowman, J., et al., Human tumor xenograft models in NCI drug development, in Anticancer Drug Development Guide. 1997, Springer. p. 112-113.

21-Lamees Dawood, et al., Anti-proliferative effect of $\mathrm{ZnO}$ NPs against the growth of Ehrlich Solid carcinoma. IJPb, 2019. 1(1): p. 7-19.

22-Salem, M.L., et al., In vitro and in vivo antitumor effects of the Egyptian scorpion Androctonus amoreuxi venom in an Ehrlich ascites tumor model. 2016. 5(1): p. 570.

23-HUANG, A.-C., et al., Epigallocatechin Gallate (EGCG), Influences a Murine WEHI-3 Leukemia Model In Vivo Through Enhancing Phagocytosis of Macrophages and Populations of T- and B-Cells. 2013. 27(5): p. 627-634.

24-Jiang, P., et al., NEAT1 upregulates EGCG-induced CTR1 to enhance cisplatin sensitivity in lung cancer cells. 2016. 7(28): p. 43337.

25-Gachpazan, M., et al., The impact of statin therapy on the survival of patients with gastrointestinal cancer. 2019. 20(7): p. 738-747.

26-Tapia-Perez, J.H., et al., Simultaneous administration of statins and pioglitazone limits tumor growth in a rat model of malignant glioma. 2016. 36(12): p. 6357-6365.

27-Karimi, B., et al., Therapeutic effect of simvastatin on DMBA-induced breast cancer in mice. 2019. 33(1): p. 84-93.

28-28. Pisanti, S., et al., Novel prospects of statins as therapeutic agents in cancer. 2014. 88: p. 84-98.
29-Ahmed, R.S.I., et al., Discovery of Green Tea Polyphenol-Based Antitumor Drugs: Mechanisms of Action and Clinical Implications, in Medicinal Plants. 2019, Springer. p. 313-332.

30-Kaymak, I., et al., Mevalonate pathway provides ubiquinone to maintain pyrimidine synthesis and survival in p53-deficient cancer cells exposed to metabolic stress. 2020. 80(2): p. 189-203. 